\title{
The Nature and Determinants of Customer Expectations of Service
}

\author{
Valarie A. Zeithaml \\ Schmalensee Zeithaml \\ Leonard L. Berry
}

Texas A\&M University

A. Parasuraman

Texas A\&M University

A conceptual model articulating the nature and determinants of customer expectations of service is proposed and discussed. The model specifies three different types of service expectations: desired service, adequate service, and predicted service. Seventeen propositions about service expectations and their antecedents are provided. Discussion centers on the research implications of the model and its propositions.

Levels of expectation are why two organizations in the same business can offer far different levels of service and still keep customers happy. It is why McDonald's can extend excellent industrialized service with few employees per customer and why an expensive restaurant with many tuxedoed waiters may be unable to do as well from the customer's point of view. Davidow and Uttal $(1989$, p. 84).

Customer expectations are pretrial beliefs about a product (Olson and Dover 1979) that serve as standards or reference points against which product performance is judged. According to the Gaps Model of service quality (Parasuraman, Zeithaml, and Berry 1985, 1988; Zeithaml, Berry, and

\footnotetext{
Journal of the Academy of Marketing Science

Volume 21, Number 1, pages 1-12.

Copyright $\odot 1993$ by Academy of Marketing Science.

All rights of reproduction in any form reserved.

ISSN 0092-0703.
}

Parasuraman 1988), customer assessments of service quality result from a comparison of service expectations with actual performance. While the importance of expectations has been acknowledged in previous research on service quality (e.g., Gronroos 1982) and customer satisfaction (e.g., Oliver 1981a), many research questions about the role of expectations in service evaluation remain to be answered.

Among the research areas to be addressed are the nature of service expectations and their key antecedents. In the first area, research is needed to define and delineate the types of expectations that customers hold for services. For instance, are these expectations best conceptualized as predictions or are they ideal standards? In the second area, research is required to identify and understand key factors affecting service expectations. What factors most influence the formation of service expectations? What role do these factors play in changing expectation levels? This article addresses these and related issues.

\section{THEORETICAL BACKGROUND}

Customer expectations have been investigated in a number of research settings (see Winer 1985) but have received the most thorough treatment in the customer satisfaction and dissatisfaction (CS/D) and service quality literatures. In these literatures, consensus exists that expectations serve as standards with which subsequent experiences are compared, resulting in evaluations of satisfaction or quality. Consensus on other issues - the specific nature of the expectation standard, the number of standards used, and the sources or antecedents of expectations - has not yet been reached. 


\section{Expectations-as-Predictions Standard}

In the dominant paradigm in the CS/D literature, expectations are viewed as predictions made by customers about what is likely to happen during an impending transaction or exchange. According to Oliver (1981b, p. 33), "It is generally agreed that expectations are consumer-defined probabilities of the occurrence of positive and negative events if the consumer engages in some behavior." Miller (1977) called this standard the expected standard, defined it as an objective calculation of probability of performance, and contrasted it with three other types of expectations (to be described later). Swan and Trawick (1980) and Prakash (1984) termed this standard predictive expectations, defined as estimates of anticipated performance level.

While the predictions paradigm dominates, considerable disagreement about standards has characterized the CS/D literature. Researchers have often departed from the prediction paradigm, arguing that alternative standards exist. Empirical support for distinctions between expectations-aspredictions and other standards has been offered (Gilly 1979; Gilly, Cron, and Barry 1983; Swan and Trawick 1980).

\section{Expectations-As-Ideal Standard}

A normative standard of expectations has been proposed by a variety of researchers. Miller (1977) proposed ideal expectations, defined as the "wished for" level of performance. Swan and Trawick (1980) proffered a standard they termed desired expectations, defined as the level at which the customer wanted the product to perform. Prakash (1984) formulated normative expectations, i.e., how a brand should perform in order for the consumer to be completely satisfied. More generally, several researchers (Westbrook and Reilly 1983; Woodruff, Cadotte, and Jenkins 1983, 1987; Sirgy 1984) argued that CS/D is more likely to be determined by how well focal brand performance fulfills innate needs, wants, or desires of consumers, rather than how performance compares with pre-purchase predictions. Kahneman and Miller (1986, p. 136) claim that each stimulus (e.g., a service encounter) is "interpreted in a rich context of remembered and construed representations of what it could have been, or should have been."

The expectations construct has been viewed as playing a key role in customer evaluation of service quality (Gronroos 1982; Lehtinen and Lehtinen 1982; Parasuraman, Zeithaml, and Berry 1985, 1988; Brown and Swartz 1989). Its meaning in the service quality literature is similar to the ideal standard in the CS/D literature. Expectations are viewed as desires or wants of consumers, i.e., what they feel a service provider should offer rather than would offer (Parasuraman, Zeithaml, and Berry 1988).

\section{Other Expectation Standards}

Several other expectation standards have been proposed and tested empirically in CS/D research. Woodruff, Cadotte, and Jenkins (1983) augmented earlier conceptualizations by proposing that customers rely on standards that reflect what the focal brand should provide to meet needs and wants, but that these expectations are constrained by the performance customers believe is possible based on experiences with real brands. They called these expectations experience-based norms because they captured both the ideal and realistic aspects of expectations. Miller (1977) also proposed minimum tolerable expectations, defined as the lower level of performance acceptable to the consumer, and deserved expectations, reflecting the consumers' subjective evaluation of their own product investment. Finally, Prakash (1984) proposed a standard called comparative expectations, consumer expectations from other similar brands.

\section{Expectations: Single Standard Versus Multiple Standards}

Recent conceptualizations of CS/D (Oliver 1985; Wilton and Nicosia 1986; Forbes, Tse, and Taylor 1986; Tse and Wilton 1988) have held that CS/D is a post-choice process involving complex, simultaneous interactions that may involve more than one comparison standard. Kahneman and Miller (1986, p. 136) contend that "A number of representations can be recruited in parallel, by either a stimulus event or an abstract probe such as a category name, and a norm is produced by aggregating the set of recruited representations." Empirical work has supported this view. As previously noted, Prakash (1984) documented three types of expectations: predictive, normative, and comparative.

Cadotte, Woodruff, and Jenkins (1987) proposed and tested alternative CS/D models involving different standards of comparison. Their product-norm model and bestbrand norm model were consistently better than the brand expectation (prediction) model at explaining variation in satisfaction feelings and total model fit. These different norms were moderately correlated, suggesting that they share a common core but that each also has a unique component.

Using path analysis, Tse and Wilton (1988) found support for the influence of both predicted and ideal expectations. They concluded that:

the results suggest that more than one comparison standard may be involved in CS/D formation because both expectation (prediction) and ideal relate individually to satisfaction... expectations and ideal appear to represent different constructs contributing separately to the CS/D formation process. The single-standard model fails to represent the underlying processes adequately in comparison with a multiple-standard paradigm (p. 209-210).

\section{Expectations: Antecedent Factors}

One relatively unexplored area of research involves the sources of consumer expectations. Cadotte, Woodruff, and Jenkins (1987) discussed experience as a source of the expectation norm and pointed out that focal brand expectations may be but one of several norms that operate. They suggest that the norm may also be derived from the typical performance of a particular brand (the favorite brand, the last-purchased, the most popular brand). A second possibility is that the norm might be an average performance 
believed typical of a group of similar brands (a product-type norm). They found that these norms, which they called product norm and best-brand norm, were consistently better at explaining variation in satisfaction than prediction of focal brand performance.

Beyond the specification of experience as influencing expectations, research in marketing on the antecedents of expectations has been limited. Oliver (1980a) ascribed expectations to three factors: the product itself, the context, and individual characteristics. Parasuraman, Zeithaml, and Berry (1985) acknowledged the importance of external company communications to customers in shaping expectations. Literature on other consumer behavior topics, such as search for information about quality, has yielded some sources that may be relevant in the formation of expectations. These include external sources such as direct inspection of a product (Beales et al. 1981) and personal consumer characteristics (Winer 1985).

\section{Gaps in the Expectations Literature}

The expectations component of the disconfirmation paradigm has been conceptualized in a variety of ways in the CS/D literature, with expectations-as-predictions being the dominant conceptualization. Research attempts to ascertain the appropriateness of these conceptualizations for understanding CS/D have been, for the most part, empirical, focusing on the ability of competing models to explain the variance in CS/D. This empirical research has provided several important insights about customer satisfaction: a variety of expectation standards exist, disconfirmation of expectations (rather than the expectations themselves) influences the satisfaction process, and focal brand predictions may not be the standard that customers use. However, a comprehensive theoretical framework that captures and explicates these results and integrates the different types of comparison standards remains to be developed.

Several CS/D researchers, after conducting empirical investigations grounded in the extant disconfirmation paradigm, have issued calls for more theoretical work in this area. For example, Cadotte, Woodruff, and Jenkins (1987) state: "Additional work is needed to refine and expand the conceptualizations of norms as standards" (p. 313). Tse and Wilton (1988) echo this need by pointing out that "Researchers have not converged on the exact conceptualization of the comparison standard and disconfirmation constructs" (p. 204).

Another gap in existing literature involves delineation of the antecedents of expectations. With the possible exception of customer experience, these sources have not been identified and discussed in detail. Furthermore, antecedents of customer expectations of service are as yet unspecified, although the services marketing literature suggests several distinguishing characteristics of service that may complicate the expectations formation process. These include customer involvement in the service production process and product intangibility (see Zeithaml, Parasuraman, and Berry 1985).

In the same literature, Parasuraman, Zeithaml, and Berry (1985) defined service quality as the comparison between customer expectations and perceptions of service. Their definition of expectations was broad and general-expecta- tions are customer desires - and did not stipulate the antecedents or norms of expectations used by customers in assessing service quality. In other words, what is the relationship among the different standards of expectation and perceived service? Do different expectations standards exist for perceived service quality as they appear to for customer satisfaction?

Another unresolved question concerns the relationship between the core constructs of customer satisfaction and perceived service quality. While many academics and practitioners use the constructs interchangeably, and while both constructs invoke the disconfirmation paradigm, some researchers (e.g., Parasuraman, Zeithaml, and Berry 1988) suggest that a distinction exists.

The research reported in this paper is an attempt to explore these knowledge gaps, better understand expectations as they pertain to customer assessment of service quality, and extend the theoretical work that exists in the customer satisfaction literature.

\section{RESEARCH METHODOLOGY}

Exploratory research was required to develop an understanding of different types of customer expectations and their sources. Focus group interviews with customers of various service industries were conducted to provide input for a conceptual model of customer expectations of service. The approach used is consistent with procedures recommended for marketing theory development by several scholars (Deshpande 1983; Peter and Olson 1983; Zaltman, LeMasters, and Heffring 1982).

\section{Service Categories Investigated}

The exploratory research design for this study was chosen to include contexts where different sources and types of customer expectations might exist. First, "pure services" (e.g., insurance) may generate different expectations than services associated with tangible products (e.g., equipment repair). Second, business customers' expectations might differ from those of end customers. Third, experienced and inexperienced customers could have differing expectations because of varying levels of familiarity with the service (Parasuraman, Zeithaml, and Berry 1985). Because the sources and types of expectations could differ in important ways within these three comparison pairs, respondents for the focus groups were chosen to represent each of them.

A total of eight sponsoring firms from the insurance, business equipment repair, truck rental and leasing, automobile repair, and hotel industries were selected. Customers of five of these firms (three insurance firms, an automobile repair firm, and a hotel chain) were chosen to represent the end-customer or consumer segment. Customers of the remaining firms (one each from insurance, business equipment repair, and truck rental and leasing) were chosen to represent the business-customer segment.

Sixteen focus group interviews were held, four each for the following cells: business customer/pure service; business customer/product-related service; end customer/pure service; end customer/product-related service. In each of 
these four cells, two of the focus group interviews were with experienced customers and two were with inexperienced customers.

Experienced and inexperienced customers of each firm were defined using the firm's operationalization of these segments. Distinctions between experienced and inexperienced customers were typically made on the basis of number of service contacts within a certain time period.

The selection of a diverse set of service categories for the focus groups was motivated by a desire to generate insights that would transcend specific services, consistent with Lovelock's (1983) call for more cross-industry research in the services sector. Moreover, the selected industries vary along key criteria used by Lovelock (1983) to classify services. For instance, in terms of the nature and results of the service act (one of several two-dimensional classification schemes proposed by Lovelock), business equipment repair, automobile repair, and truck rental and leasing would represent "tangible" actions directed at "physical possessions;" hotel services would represent "tangible" as well as "intangible" actions directed at "people's bodies and minds;" and insurance would represent "intangible" actions directed at "physical possessions and intangible assets".

\section{Conducting of Focus Groups}

The 16 focus group interviews were held in Atlanta, Chicago, Seattle, Rochester (NY), and Dallas to provide geographical balance. The groups were formed in accordance with guidelines traditionally followed in the marketing research field (Bellenger, Bernhardt, and Goldstucker 1976). Field research companies in the various locations were hired to recruit and screen participants for the focus groups. Participants were chosen from customer lists provided by the sponsor firms in accordance with criteria pertaining to customer experience. The average number of participants per group was nine. All interviews were conducted in the focusgroup facilities of the research companies, but were moderated by the researchers.

Because the focus groups were exploratory, and intended as an aid in generating constructs and hypotheses, they were conducted in a non-directive and unstructured fashion as recommended by Calder (1977). Broad, open-ended questions were posed (e.g., "What do you expect from a service provider?" "Where do your expectations come from?" "Have your expectations changed over time?"). Discussion in each group centered on customers' expectations and experiences relating to the service in general (e.g., business insurance), as opposed to the specific service of the sponsor firm. The identities of the participating firms were not revealed to the respondents.

\section{Analysis of Focus Group Interviews}

An extensive written transcript of each focus group was prepared by one researcher as the interview was being conducted by another. All focus groups were also audiotaped. The written transcripts, supplemented by the audiotapes, formed the basis for the model of expectations developed in this article.

The primary objective of the focus groups was to gener- ate constructs and hypotheses that would serve as building blocks for the model. As such, the approach for conducting and analyzing the interviews incorporated several recommended guidelines for theory construction through qualitative research (Belk, Sherry, and Wallendorf 1988; Thompson, Locander, and Pollio 1989).

First, at the conclusion of each focus group interview the researchers informally discussed their impressions about the interview to identify emerging themes for verification in subsequent groups and for potential use in the model. This procedure is similar to what Belk, Sherry, and Wallendorf (1988) term memoing: "Memoing involves sporadic oral or written briefings of other team members regarding one's emerging interpretations of data or sense of project progress" (p. 454). To maximize the benefits of this memoingtype process, and to verify that members of our research team (consisting of three researchers) were interpreting the focus group interviews consistently, all three researchers took part in the first 5 of the 16 focus group interviews (two as observers/note-takers and one as moderator). Two of the three researchers took part in each of the remaining focus group interviews.

Second, consistent themes identified from initial focus groups through the memoing process were informally verified in subsequent interviews. In most instances the themes emerged on their own during the discussion and reinforced the preliminary insights. In other instances the moderator introduced the themes to check whether they were consistent with the respondents' experiences.

Third, each researcher independently reviewed the written transcripts and developed a list of constructs and hypotheses after all 16 focus groups were completed. The researchers then shared their inferences with one another and discussed them in several lengthy meetings to achieve "triangulation across researchers" (Belk, Sherry, and Wallendorf 1988) and identify key components of the model. Thus the constructs and relationships embedded in the model are based on insights that reflect researcher consensus and are supported by consistent patterns of responses obtained from multiple focus groups.

\section{THE MODEL}

Common themes emerging from the focus group interviews and insights from previous research led to the development of the conceptual model of customer service expectations shown in Figure 1. Although differences were anticipated across the comparison pairs described above, the nature and sources of expectations were similar across the groups. Expectations of end- and business-customer groups, of experienced and inexperienced customers, and of customers of pure and product-related services had fundamentally the same nature and antecedents.

The generic model of customer expectations is divided into four main sections: (1) the expected service component, (2) antecedents of desired service, (3) antecedents of adequate service, and (4) antecedents of both predicted and desired service. These four sections will be discussed along with propositions about the nature and relationships of the components of the model. 


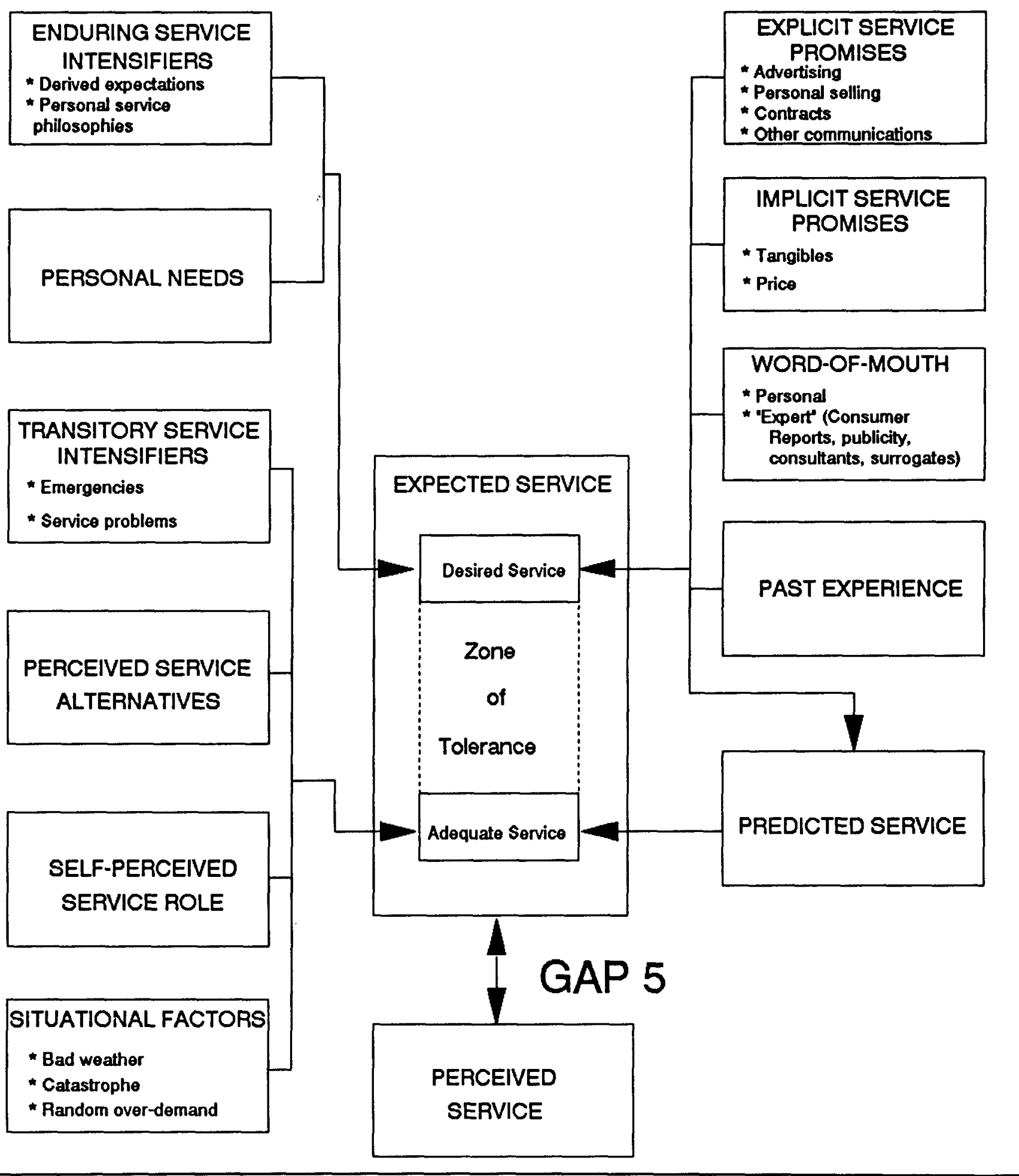




\section{The Expected Service Component}

Previous research on service quality (Sasser, Olsen, and Wyckoff 1978; Gronroos 1982; Lehtinen and Lehtinen 1982; Parasuraman, Zeithaml, and Berry 1985, 1988; Brown and Swartz 1989) supports the notion that perceived service quality stems from customers' comparisons of what they wish to receive from firms and what they perceive actual service performance to be. In other words, perceived service quality is viewed as the degree and direction of discrepancy between customers' perceptions and desires (Parasuraman, Zeithaml, and Berry 1985, 1988).

The focus group interviews supported the normative standard as the appropriate comparison frame. Based on the interviews and past literature, we are terming this standard of expectation desired service, which is defined as the level of service the customer hopes to receive. Desired service is a blend of what the customer believes "can be" and "should be". Desired service is similar to what Liechty and Churchill (1979) view as the level of performance the customer ought to receive, or deserves, given a perceived set of costs.

Although customers hope to realize their service desires, they recognize that this is not always possible. Thus, they hold another, lower level expectation for the threshold of acceptable service. We define this lower level expectation as adequate service, the level of service the customer will accept. This level of expectation is comparable to Miller's (1977) minimum tolerable expectation, the bottom level of performance acceptable to the customer, as well as Woodruff, Cadotte, and Jenkins' (1987) experience-based norms. The focus groups consistently showed that customers' view of what a service "should be" exists at two levels: a desired level and an adequate level. A participant in one of the focus groups articulated the difference between these two types of expectations: "Expectation and tolerance differyour expectations don't change but your tolerance changes-what you'll accept changes." This leads to our first proposition:

P1: Customers assess service performance based on two standards: what they desire and what they deem acceptable.

Services are heterogeneous in that performance may vary across providers, across employees from the same provider, and even within the same service employee (Zeithaml, Parasuraman, and Berry 1985). The extent to which customers recognize and are willing to accept heterogeneity we call the zone of tolerance. This zone, representing the difference between desired service and the level of service considered adequate, can expand and contract. In other words, customers' service expectations are characterized by a range of levels (bounded by desired and adequate service) rather than a single level. A focus group participant expressed the existence of this range: "There is a certain level of service you expect .... as long as the service is within a certain 'window' of that level you don't complain." This leads to our second proposition:

P2: A zone of tolerance separates desired service from adequate service.
We found considerable variation in customers' tolerance zones. Some customers had a narrow zone of tolerance, requiring a consistent level of service from providers, whereas other customers tolerated a greater range of service. We also found that an individual customer's zone of tolerance increases or decreases depending on a number of factors, including company-controlled factors such as price. A business insurance customer commented, "Price increases don't really drive up expectations. But my tolerance level will become more stringent/less flexible with an increase." A business equipment repair customer claimed, "My expectations are higher when I've paid for a maintenance agreement, because I've paid money up front."

The customer's zone of tolerance may also vary for different service attributes. Parasuraman, Zeithaml, and Berry (1988) found that customer evaluation of service quality occurs along five dimensions: reliability, responsiveness, assurance, empathy, and tangibles. Our focus group interviews suggest that customers might have narrower zones of tolerance for some dimensions than for others. In particular, respondents seemed less tolerant about unreliable service (broken promises, service errors) than other service breakdowns. In fact, for service attributes that certain customers may assess in categorical terms (i.e., either the service provider possesses the attribute or it does not), the zone of tolerance could be zero (i.e., adequate and desired service will be at the same level).

The fluctuation in the individual customer's zone of tolerance is more a function of changes in the adequate service level, which moves readily up and down due to contextual circumstances, than a function of changes in the desired service level, which tends to move more incrementally and do so in an upward direction due to the accumulation of experiences. Desired service is relatively idiosyncratic and stable as these comments from two business insurance customers illustrate:

- My expectations about certain basics, for example, good faith, haven't changed.

- Expectations won't change when the market is tight but you become more tolerant.

Fluctuation in the zone of tolerance can be likened to an accordion's movement, but with most of the gyration coming from one side (the adequate service level) rather than the other (the desired service level). These conclusions can be summarized by means of three propositions:

P3: The zone of tolerance varies across customers.

P4: The zone of tolerance expands or contracts within the same customer.

P5: The desired service level is less subject to change than the adequate service level.

\section{Antecedents of Desired Service}

Davidow and Uttal (1989) acknowledge the myriad of customer-related factors that influence the expectation formation process: 
[Service] expectations are formed by many uncontrollable factors, from the experience of customers with other companies and their advertising to a customer's psychological state at the time of service delivery. Strictly speaking, what customers expect is as diverse as their education, values, and experience. The same advertisement that shouts "personal service' to one person tells another that the advertiser has promised more than it possibly can deliver (p. 85).

Delineation of these multiple influences was one of the objectives of this research. Patterns of responses in the focus group interviews indicated that the level of desired service depends on six antecedents, two of which are discussed in this section: (1) enduring service intensifiers and (2) personal needs. The four remaining antecedents, which also influence predicted service, another type of expectation, are discussed in a subsequent section.

Enduring service intensifiers are individual, stable factors that lead the customer to a heightened sensitivity to service. One of those factors is derived service expectations, where the customer's expectations are driven by another party. An example of this is when service employees depend on others to serve their own customers. An equipment repair customer, for example, stated, "I'm analyzing blood. We're under a lot of pressure (from the doctors). It's important than when repair people come in (to repair blood analysis equipment) they be well equipped." In this case, the doctors' expectations for timely blood test results elevated the equipment repair customer's expectations for timely repair service.

Employees may also derive their expectations from their managers and supervisors. Asked when their own expectations were highest, several respondents commented that, "The needs of upper administration can change your expectations" or, "When top management expects more of me."

Another enduring service intensifier is personal service philosophy - the customer's underlying generic attitude about the meaning of service and the proper conduct of service providers. Customers who are themselves in service businesses or have worked for them in the past seem to have especially strong philosophies: "You expect to be treated the way you treat other people" was one respondent's comment. A business insurance customer claimed, "Your own basic philosophies and attitudes about how to do business carries over into what you expect from insurance companies." To the extent that customers have personal philosophies about service provision, their expectations of most service providers will likely be intensified. We therefore propose that:

\section{P6: Enduring service intensifiers elevate the level} of desired service.

Personal needs, states or conditions essential to the physical or psychological well-being of the customer are a second factor that shape desired service. Personal needs can fall into many sub-categories, including physical, social, and psychological. A customer with high social and dependency needs, for example, may have relatively high expectations for a hotel's ancillary services-hoping, for exam- ple, that the hotel has a bar with live music and dancing. The impact of personal needs on desired service is illustrated by the different expectations held by two business insurance customers:

- Most of my expectations pertain to brokers. I expect the broker to do a great deal of my work because I don't have the staff . . . I expect the broker to know a great deal about my business and communicate that knowledge to the underwriter.

- My expectations are different ... I do have a staff to do our certificates, etc., and use the broker minimally.

Given these observations, we propose that:

P7: A positive relationship exists between the level of personal needs and the level of desired service.

\section{Antecedents of Adequate Service}

The customer's level of adequate service is influenced by five factors: (1) transitory service intensifiers, (2) perceived service alternatives, (3) customer self-perceived service roles, (3) situational factors, and (4) predicted service.

Transitory service intensifiers are temporary, usually short-term, individual factors that lead the customer to a heightened sensitivity to service. Personal emergency situations where the customer strongly needs service and perceives that the company ought to be able to respond (such as automobile insurance service in an accident) raise the level of adequate service, particularly the level of responsiveness considered acceptable. Comments by two focus group participants illustrate the impact of transitory service intensifiers:

- An automobile insurance customer: "The nature of my problem influences my expectations, for example, a broken window versus a DWI accident requiring brain surgery."

- A business equipment repair customer: "I had calibration problems with the X-ray equipment. They should have come out and fixed it in a matter of hours because of the urgency."

Problems with the initial service can also lead to heightened expectations. As one auto repair customer put it: "I am willing to be understanding the first time but would expect much more and be more impatient the second time around." Therefore, we propose that:

P8: In the presence of transitory service intensifiers, the level of adequate service will increase and the zone of tolerance will narrow.

Perceived service alternatives are customers' perceptions of the degree to which they can obtain better service through providers other than the focal company. If customers have several service providers to choose from, or if they can provide the services for themselves (such as lawn care or 
bookkeeping), their levels of adequate service may be higher than those of customers who believe it is not possible to get sufficiently better service elsewhere. The influence of this factor was clearly articulated by a business insurance customer who said, "Sometimes you just don't have many options . . . so you have to effectively settle for less." This leads to our ninth proposition:

P9: The customer's perception that service alternatives exist raises the level of adequate service and narrows the zone of tolerance.

A third factor affecting the level of adequate service is the customer's self-perceived service role. We define this as customers' perceptions of the degree to which they themselves influence the level of service they receive. The importance of this factor, which relates to customer involvement with the service, has been stressed in previous research (e.g., Bowen 1989).

When the provision of the service depends critically on customers' participation, their expectations are partly shaped by how well they believe they are performing their own roles. An automobile insurance customer acknowledged his responsibility in service provision: "You can't blame it all on the insurance agent. You need to be responsible too and let the agent know what exactly you want." A truck leasing customer recognized her role by stating, "There are a lot of variables that can influence how you get treated, including how you deal with them."

Customers' zones of tolerance seem to expand when they sense they are not fulfilling their roles. When, on the other hand, customers believe they are doing their part in delivery, their expectations of adequate service are heightened. The comment of an automobile repair customer illustrates: "Service writers are not competent. I prepare my own itemized list of problems, take it to the service writer and tell him or her: "Fix these." This leads us to propose that:

P10: The higher the level of a customer's selfperceived service role, the higher the level of adequate service.

The focus group interviews indicated that levels of adequate service were also influenced by situational factors, defined as service-performance contingencies that customers perceive are beyond the control of the service provider. For example, whereas personal emergencies such as serious automobile accidents would likely intensify customer service expectations of insurance companies (proposition 8), catastrophes that affect a large number of people at one time (earthquakes or hurricanes) would likely lower service expectations since customers recognize that insurers are inundated with demand for their services. Customers appear to recognize that these contingencies are not the fault of the service company and accept lower levels of adequate service given the context. We therefore propose that:

P11: Situational factors temporarily lower the level of adequate service, widening the zone of tolerance.

\section{FIGURE 2 \\ Comparison between Customer Evaluation of Perceived Quality and Satisfaction}

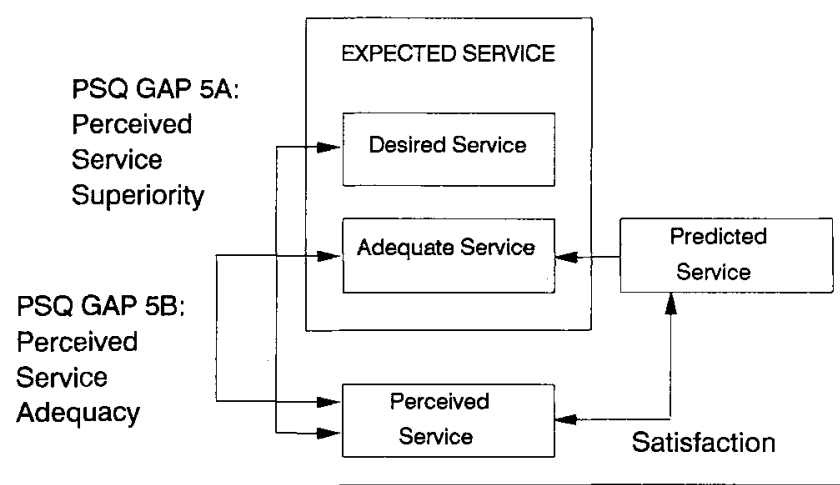

The final variable hypothesized to influence adequate service is predicted service, the level of service customers believe they are likely to get. This variable is synonymous with the definition of expectations in the dominant paradigm in the CS/D literature (Oliver 1980a,b; Olson and Dover 1979).

Figure 2 illustrates the critical differences between customer satisfaction and perceived service quality assessments that result from the different standards of comparison used by customers in forming these assessments. As conceptualized in the CS/D literature, assessments of customer satisfaction result from a comparison between predicted service and perceived service. As conceptualized in the services marketing literature, assessments of service quality result from a comparison of desired service and perceived service. Parasuraman, Zeithaml, and Berry (1985) refer to this comparison as Gap 5 in their model of service quality.

Based on the present research, Gap 5--the gap between customer expectations and perceptions-can be conceptualized to reflect two comparison standards: desired and adequate service. The comparison between desired service and perceived service, which we call perceived service quality (PSQ) Gap 5A, is the perceived service superiority gap; and the comparison between adequate service and perceived service, which we call PSQ Gap 5B, is the perceived service adequacy gap. The smaller the gap between desired service and perceived service, the higher the perceived service superiority of the firm. The smaller the gap between adequate service and perceived service, the higher the perceived service adequacy of the firm. These two service quality assessments (of perceived service superiority and perceived service adequacy) therefore replace the single Gap 5 in the Gaps Model. For these reasons, we propose that:

P12: Two types of service quality assessments are made by consumers: perceived service superiority, which results from a comparison between desired service and perceived service; and perceived service adequacy, which results from a comparison between adequate service and perceived service. 
Customer satisfaction is distinct from service quality assessments in that satisfaction results from a comparison between predicted service and perceived service. While the focus groups did not specifically address the way in which predicted service influences satisfaction, the literature on satisfaction suggests that it plays a direct role (Figure 2). While predicted service plays a direct role in satisfaction assessment, it only indirectly affects service quality assessment (Gap 5B) by influencing adequate service. If customers predict good service, for example, their levels of adequate service are likely to be higher than if they predict poor service. A business insurance customer illustrates: "When the market is soft you can expect and get great service." An auto repair customer reflected: "The dealer is supposed to be an expert. I'm paying more for a dealer's service. Therefore, I should expect the dealer to do it right the first time." If customers predict that service levels will be low, their levels of adequate service decrease and their zones of tolerance widen. Therefore:

P13: The higher the level of predicted service, the higher the level of adequate service and the narrower the zone of tolerance.

\section{Antecedents of Both Desired and Predicted Service}

Beales et al. (1981) describe two general categories of search for information about product quality: external search and internal search. External search includes product information acquired through outside sources; the information can be acquired actively, such as calling a store, or passively, such as watching television. Three factors that can be categorized as external affect both desired service and predicted service: (1) explicit service promises, (2) implicit service promises, and (3) word-of- mouth communications. One internal search factor, past experience, also influences both desired and predicted service.

Explicit service promises are personal and nonpersonal statements about the service made to customers by the organization. These promises take different forms, among them advertising, personal selling, contracts, and communications from service or repair departments. All have a direct impact on desired service as well as predicted service. The nature of the effects of explicit promises, while not heavily researched, may vary depending on the difficulty consumers have in evaluating product or service quality. Deighton (1984) and others (Hoch and Ha 1986, Ha and Hoch 1989), for example, suggest that advertising effects the way customers interpret objective and ambiguous evidence about quality. The more ambiguous the available evidence about quality, the larger and more dramatic the effects of advertising; this effect is believed to be due to advertising-induced hypothesis testing and search.

A hotel customer describes the impact of these promises on his expectations: "They get you real pumped up with the beautiful ad. When you go in you expect the bells and whistles to go off. Usually they don't." A business equipment repair customer states: "When you buy a piece of equipment you expect to get a competitive advantage from it. Service is promised with the sale of the equipment." We therefore propose that:

P14: The higher the level of explicit service promises, the higher the levels of desired service and predicted service.

Implicit service promises are service-related cues other than explicit promises that lead to inferences about what the service should and will be like. These quality cues include price and the tangibles associated with the service. Research has shown that customers often use price and tangibles as surrogates of quality (Zeithaml 1988). Consider a customer who shops for insurance, finding two firms charging radically different prices. The customer may make the inference that the firm with the higher prices should and will provide higher quality service. Similarly, a customer who stays at a posh hotel is likely to desire and predict a higher standard of service from it as compared to a hotel with lower rates and less impressive facilities.

Focus group participants repeatedly emphasized the importance of implicit promises, particularly price, in shaping their expectations. One hotel customer said, "What will a hotel provide? That depends on what you will pay." Another said, "You expect the service to be better in a nice-looking hotel." This leads to our next proposition:

P15: Implicit service promises elevate the levels of desired service and predicted service.

The importance of word-of-mouth communication in shaping expectations of service is well documented (Davis, Guiltinan, and Jones 1979; George and Berry 1981; Donnelly 1980; Zeithaml, Parasuraman, and Berry 1985). These personal and sometimes nonpersonal statements made by parties other than the organization convey to customers what the service will be like (i.e., what they can expect). Word of mouth about service performance carries particular weight as an information source because it is perceived as unbiased. Word of mouth tends to be quite important in services because services are difficult for customers to evaluate prior to purchasing and directly experiencing them. Experts (including Consumer Reports, friends, and family) are all sources that affect the levels of desired service and predicted service. In the words of one focus group participant, "What you hear from others about higher service levels in their companies can influence my expectation levels ... I will check around to see why my company isn't providing the same level of service." We therefore propose that:

P16: Positive word of mouth communication elevates the levels of desired and predicted service.

Past experience, the customer's previous exposure to service that is relevant to the focal service, is another force in shaping predictions and desires (Scott and Yalch 1980; Smith and Swinyard 1983). The service experiences relevant for prediction can involve previous exposure to the 
focal firm's service (e.g., the XYZ Hotel), to other firms in the industry (other hotel chains), or exposure to any service firm (e.g., department stores or banks). In the CS/D literature, Cadotte, Woodruff, and Jenkins (1987) provide evidence of the use of different experience norms leading to customer satisfaction. Possible norms include experience with the focal brand, typical performance of a particular brand (favorite brand, last-purchased brand, top-selling brand) or average performance a customer believes represents a group of similar brands. Sample quotes from the focus groups include:

My expectations are definitely influenced by my past experience . . . my expectations are more realistic because of the knowledge I've gained.

The more years you spend in this business the more you expect because the more you learn and know.

This leads to our final proposition:

P17: A positive relationship exists between levels of past experience with a service and the levels of desired service and predicted service.

\section{RESEARCH IMPLICATIONS}

The model presented in this paper provides a comprehensive framework of service expectations and their potential antecedents. The model offers a more precise foundation for measuring customer expectations of service than that which existed previously. The model also clarifies the distinction between customer satisfaction and service quality assessment within a single framework by specifying three different levels of customer expectations: (l) desired service, which reflects what customers want; (2) adequate service, the standard that customers are willing to accept; and (3) predicted service, the level of service customers believe is likely to occur.

The constructs and propositions embedded in the model augment the extant literature on customer expectations. In addition, they raise a number of intriguing questions and methodological challenges for future research.

First, empirical testing of the propositions advanced would require developing psychometrically sound measures of the model's constructs, particularly the focal constructs of desired, adequate, and predicted service. While the domain of customers' service expectations (i.e., the general dimensions and criteria customers use in evaluating services) has been well established (Parasuraman, Zeithaml, and Berry 1985, 1988), more work is needed to operationalize those domains in the context of the three types of expectations-desired, adequate, and predicted service. A noteworthy challenge in undertaking such research is to ensure that the wording of the instructions and/or scale items is sufficiently distinct for the three types of expectations to establish high discriminant validity among them (especially between desired and adequate service).

Second, since desired service is likely to be more stable than adequate service, and therefore less subject to change (P5), research focusing on strategies to manage adequate service level expectations, and the relative effectiveness of those strategies, would be especially helpful to service companies. The posited difference between the stability of desired and adequate service also implies a need for research focusing on measurement of these two constructs. For example, should a service firm measure adequate service more frequently than desired service? Should measures of adequate service be more situation-specific than those of desired service?

Third, the possible role of predicted service in influencing how customers evaluate the gap between perceived and expected service (i.e., the service quality gap) is worthy of investigation. The proposed framework clearly distinguishes between service quality assessment and satisfaction assessment by implying that predicted service is directly relevant only for the latter. The influence of predicted service on service quality assessment is only indirect through its positive correlation with adequate service (P12). However, an intriguing possibility is that the predicted service level may moderate how a customer interprets Gap 5, the service quality assessment gap. For instance, suppose the level of service perceived by a customer falls at the midpoint of his/her tolerance zone. Would this customer's interpretation of this performance level (and hence assessment of service quality) vary depending on whether the predicted service level was above or below the adequate service level? Relatedly, can the predicted service level ever exceed the adequate service level? These and other research questions would provide important insights into customer evaluation of service quality.

Fourth, researching ways service firms could use the zone of tolerance concept to formulate effective marketing strategies would be beneficial. Intuitively, it would seem that managers would want their customers to have wide tolerance zones for service. On the other hand, if customers have relatively wide zones of tolerance for service, does this make it more difficult for firms with superior service to earn customer loyalty? Would superior service firms be better off to attempt to narrow customers' tolerance zones to reduce the competitive appeal of mediocre providers?

The zone of tolerance is an intriguing new construct but the nature and degree of its managerial relevance requires much additional investigation. For instance, can customers be meaningfully segmented into groups according to their zones of tolerance with different marketing strategies developed for each of them? What is the impact of strategies such as relationship marketing and service guarantees on the zone of tolerance?

A related research issue involves measurement of the zone of tolerance. One approach is to operationalize the zone as the difference between measures of the desired and adequate service constructs. However, such an approach may be problematic in view of the proposed difference in the stability of the two measures (as previously discussed) and potential problems with operationalizing constructs as difference scores in models involving multiple constructs (see, e.g., Johns 1981; Prakash 1984). A need and a challenge exist for developing direct measures of the zone of 
tolerance, perhaps by having customers specify the range of expectations that they possess for service.

Fifth, since the propositions developed in this paper are based on exploratory focus group research, there is a clear need for testing them through empirical, confirmatory research. Such research will help identify the antecedent constructs that have significant effects on the different types of expectations. In addition, from a managerial standpoint, it is useful to determine the relative importance of the significant antecedent constructs. For instance, what is the relative weight of word of mouth, explicit service promises, and implicit service promises in shaping desired service and predicted service? What is the relative impact of selfperceived service role, enduring service intensifiers, and transitory service intensifiers on adequate service levels? Empirically based answers to these questions are essential for establishing the relative efficiency of various expectation-management strategies implied by our conceptual model.

\section{ACKNOWLEDGMENT}

The authors gratefully acknowledge the financial support and cooperation provided by the Marketing Science Institute and eight of its corporate sponsors.

\section{REFERENCES}

Beales, Howard, Michael B. Mazis, Steven C. Salop, and Richard Staelin. 1981. "Consumer Research and Public Policy." Journal of Consumer Research 8 (June): 11-22.

Belk, Russell W., John F. Sherry, Jr., and Melanie Wallendorf. 1988. "A Naturalistic Inquiry into Buyer and Seller Behavior at a Swap Meet." Journal of Consumer Research 14 (March): 449-470.

Bellenger, Danny N., Kenneth L. Bernhardt, and Jac L. Goldstucker. 1976. Qualitative Research in Marketing Chicago: American Marketing Association.

Bowen, David. 1989. "Leadership Aspects and Reward Systems of Customer Satisfaction." Speech given at CTM Customer Satisfaction Conference. Los Angeles, CA, March 17, 1989.

Brown, Stephen W. and Teresa A. Swartz. 1989. "A Dyadic Evaluation of the Professional Services Encounter." Journal of Marketing 53 (April): 92-98.

Cadotte, Ernest R., Robert B. Woodruff, and Roger L. Jenkins. 1987. "Expectations and Norms in Models of Consumer Satisfaction." Journal of Marketing Research 24 (August): 305-314.

Calder, Bobby J. 1977. "Focus Groups and the Nature of Qualitative Marketing Research." Journal of Marketing Research 14 (August): 353364.

Davidow, William H. and Bro Uttal. 1989. "Service Companies: Focus or Falter." Harvard Business Review 67 (July-August): 77.

Davis, Duane L., Joseph G. Guiltinan, and Wesley H. Jones. 1979. "Service Characteristics, Consumer Research and the Classification of Retail Services." Journal of Retailing 55 (Fall): 3-21.

Deighton, John. 1984. "The Interaction of Advertising and Evidence." Journal of Consumer Research 11 (December): 763-770.

Deshpande, Rohit. 1983. "Paradigms Lost: On Theory and Method in Research in Marketing." Journal of Marketing 47 (Fall): 101-110.

Donnelly, James H., Jr. 1980. "Service Delivery Strategies in the 1980sAcademic Perspectives." In Financial Institution Marketing Strategies in the 1980s. Eds. Leonard L. Berry and James H. Donnelly, Jr. Washington, DC: Consumer Bankers Association, 143-150.

Forbes, J. D., David K. Tse, and Shirley Taylor. 1986. "Toward a Model of Consumer Post-Choice Response Behavior." In Advances in Consumer Research. Vol. 13. Ed. Richard L. Lutz. Ann Arbor, MI: Association for Consumer Research, pp. 658-661.
George, William R. and Leonard L. Berry. 1981. "Guidelines for the Advertising of Services." Business Horizons. 24 (May-June): 52-56.

Gilly, Mary C. 1979. "Complaining Consumers: Their Satisfaction with Organizational Response." In New Dimensions of Consumer Satisfaction and Complaining Behavior. Eds. Ralph L. Day and H. Keith Hunt. Bloomington: School of Business, Indiana University, 99-107.

Gilly, Mary C., William L. Cron, and Thomas E. Barry. 1983. "The Expectation-Performance Comparison Process: An Investigation of Expectation Types." In International Fare in Consumer Satisfaction and Complaining Behavior. Eds. Ralph L. Day and H. Keith Hunt. Bloomington: School of Business, Indiana University, 10-16.

Gronroos, Christian. 1982. Strategic Management and Marketing in the Service Sector. Helsingfors: Swedish School of Economics and Business Administration.

Ha, Young-Won and Stephen J. Hoch. 1989. "Ambiguity, Processing Strategy, and Advertising Evidence Interactions." Journal of Consumer Research 16 (September): 354-360.

Hoch, Stephen J. and Young-Won Ha. 1986. "Consumer Learning: Advertising and the Ambiguity of Product Experience." Journal of Consumer Research 13 (September): 221-233.

Johns, Gary. 1981. "Difference Score Measures of Organizational Behavior Variables: A Critique." Organizational Behavior and Human Performance 27 (June): 443-463.

Kahneman, Daniel and Dale T. Miller. 1986. "Norm Theory: Comparing Reality to Its Alternatives.” Psychological Review 93 (April): 136-153.

Lehtinen, Uolevi and Jarmo R. Lehtinen. 1982. "Service Quality: A Study of Quality Dimensions." Unpublished working paper, Helsinki, Finland OY: Service Management Institute.

Liechty, Margaret and Gilbert A. Churchill, Jr. 1979. "Conceptual Insights into Consumer Satisfaction with Services." In Educator's Conference Proceedings. Series 94. Eds. Neil Beckwith et al. Chicago: American Marketing Association: 509-515.

Lovelock, Christopher H. 1983. "Classifying Services to Gain Strategic Marketing Insights.” Journal of Marketing 47 (Summer): 9-20.

Miller, John A. 1977. "Studying Satisfaction, Modifying Models, Eliciting Expectations, Posing Problems, and Making Meaningful Measurements." In Conceptualization and Measurement of Consumer Satisfaction and Dissatisfaction. Ed. H. Keith Hunt. Bloomington: School of Business, Indiana University, 72-91.

Oliver, Richard L. 1980a. "A Cognitive Model of the Antecedents and Consequences of Satisfaction Decisions." Journal of Marketing Research 17 (November): 460-469.

—. 1980b. "Conceptualization and Measurement of Disconfirmation Perceptions in the Prediction of Consumer Satisfaction." In Refining Concepts and Measures of Consumer Satisfaction and Complaining Behavior. Eds. H. Keith Hunt and Ralph L. Day. Bloomington: School of Business, Indiana University: 2-6.

_. 1981a. "What is Customer Satisfaction?" The Wharton Magazine 5 (Spring): 36-41.

1981b. "Measurement and Evaluation of Satisfaction Processes in Retail Settings." Journal of Retailing 57 (Fall): 25-48.

1985. "An Extended Perspective on Post-Purchase Phenomena: Is Satisfaction a Red Herring?" Unpublished paper presented at 1985 Annual Conference of the Association for Consumer Research, Las Vegas (October).

Olson, Jerry C. and Philip Dover. 1979. "Disconfirmation of Consumer Expectations Through Product Trial." Journal of Applied Psychology 64 (April): 179-189.

Parasuraman, A., Valarie Zeithaml, and Leonard Berry. 1985. "A Conceptual Model of Service Quality and Its Implications for Future Research." Journal of Marketing 49 (Fall): 41-50.

Parasuraman, A., Valarie Zeithaml, and Leonard Berry. 1988. "SERVQUAL: A Multiple-Item Scale for Measuring Consumer Perceptions of Service Quality." Journal of Retailing 64 (Spring): 12-40.

Peter, J. Paul and Jerry Olson. 1983. "Is Science Marketing?" Journal of Marketing 47 (Fall): 111-125.

Prakash, Ved. 1984. "Validity and Reliability of the Confirmation of Expectations Paradigm as a Determinant of Consumer Satisfaction." Journal of the Academy of Marketing Science 12 (Fall): 63-76.

Sasser, W. Earl, Jr., R. Paul Olsen, and D. Daryl Wyckoff. 1978. Management of Service Operations: Text and Cases. Boston: Allyn \& Bacon.

Scott, Carol A. and Richard F. Yalch. 1980. "Consumer Response to Initial Product Trial: A Bayesian Analysis." Journal of Consumer Research 7 (June): $34-41$ 
Sirgy, M. Joseph. 1984. "A Social Cognitıon Model of Consumer Satisfaction/Dissatisfaction: An Experıment." Psychology and Marketing 1 (Summer): 27-44.

Smith, Robert E. and William R. Swinyard. 1983. "Attitude-Behavior Consistency: The Impact of Product Trial Versus Advertising." Journal of Marketing Research 20 (August): 257-267.

Swan, John E. and I. Frederick Trawik. 1980. "Satisfaction Related to Predictive vs. Desired Expectations." In Refining Concepts and Measures of Consumer Satisfaction and Complaining Behavior. Eds. H. Keith Hunt and Ralph L. Day. Bloomington: School of Business, Indiana University, 7-12.

Tse, David K. and Peter C. Wilton. 1988. "Models of Consumer Satisfaction Formation: An Extension." Journal of Marketing Research 25 (May): 204-212.

Thompson, Craig J., William B. Locander, and Howard R. Pollio. 1989. "Putting Consumer Experience Back into Consumer Research: The Philosophy and Method of Existential Phenomenology." Journal of Consumer Research 16 (September): 133-146.

Westbrook, Robert A. and Michael D. Reilly. 1983. "Value-Precept Disparity: An Alternative to the Disconfirmation of Expectations Theory of Consumer Satisfaction." In Advances in Consumer Research. Vol. 10. Eds. Richard P. Bagozzi and Alice M. Tybout. Ann Arbor, MI: Association for Consumer Research, 256-261.

Wilton, Peter and Franco M. Nicosia. 1986. "Emerging Paradigms for the Study of Consumer Satisfaction." European Research 14 (January): 411 .

Winer, Russell S. 1985. "Formation of Consumer Expectations." Working paper. Owen Graduate School of Management, Vanderbilt University.

Woodruff, Robert B., Ernest R. Cadotte, and Roger L. Jenkins. 1983. "Modeling Consumer Satisfaction Processes Using Experience-Based Norms." Journal of Marketing Research 20 (August): 296-304.

Woodruff, Robert B., Ernest R. Cadotte, and Roger L. Jenkins. 1987. "Expectations and Norms in Models of Consumer Satisfaction." Journal of Marketing Research 24 (August): 305-314.

Zaltman, Gerald, Karen LeMasters, and Michael Heffring, 1982. Theory Construction in Marketing: Some Thoughts on Thinking. New York: John Wiley \& Sons, Inc.

Zeithaml, Valarie A. 1988. "Consumer Perceptions of Price, Quality, and Value: A Means-End Model and Synthesis of Evidence." Journal of Marketing 52 (July): 2-22.

Zeithaml, Valarie A., A. Parasuraman, and Leonard L. Berry. 1985. "Problems and Strategies in Services Marketing." Journal of Marketing 49 (Spring): 33-46.

Zeithaml, Valarie A., Leonard L. Berry, and A. Parasuraman. 1988. "Communication and Control Processes in the Delivery of Service Quality." Journal of Marketing 52 (April): 35-48.

\section{ABOUT THE AUTHORS}

Valarie A. Zeithaml (Doctor of Business Administration, University of Maryland) is Partner in Schmalensee Zeithaml Consulting and was previously on the faculty at Duke University and Texas A\&M University. Her research interests include services marketing and consumer perceptions of price and quality. Her articles have appeared in the Journal of Consumer Research, Journal of Marketing, Journal of Marketing Research, Journal of Consumer Affairs, Journal of Retailing, and Management Accounting. She is co-author (with Len Berry and Parsu Parasurman) of Delivering Quality Service: Balancing Customer Perceptions and Expectations (The Free Press, 1990).

Leonard L. Berry (Ph.D., Arizona State University) holds the J. C. Penney Chair of Retailing Studies, is Professor of Marketing, and is director of the Center for Retailing Studies at Texas A\&M University. He is a former national president of the American Marketing Association. His research interests are services marketing, service quality, and retailing strategy. He is the author of numerous journal articles and books, including Marketing Services: Competing Through Quality (The Free Press, 1991), which he wrote with A. Parasuraman.

A. Parasuraman (D.B.A., Indiana University) is Foley's/ Federated Professor of Retailing and Marketing Studies at Texas A\&M University. His research interests include services marketing, sales management, and marketing strategy. He has written numerous articles in journals such as the Journal of Marketing, Journal of Marketing Research, Journal of Business Research, Sloan Management Review, and Business Horizons. He is the author of Marketing Research (Addison-Wesley, 1991) and coauthor (with Leonard L. Berry and Valarie A. Zeithaml) of Delivering Quality Service: Balancing Customer Perceptions and Expectations (The Free Press, 1990). 